\title{
Turning up the Volume on Man's Best Friend: Ethical Issues Associated with Commercial Dog Breeding
}

\author{
Candace $C$. Croney \\ Center for Animal Welfare Science, Department of Comparative \\ Pathobiology, Department of Animal Sciences, Purdue University, \\ 132 Veterinary Pathology Building, 625 Harrison Street, West Lafayette, IN \\ 47906, USA \\ ccroney@purdue.edu
}

\begin{abstract}
As the dog's popularity as a human companion has grown, demand for purebred dogs has likewise escalated. Commercial breeding of dogs, which currently helps to meet such demands has become a point of social contention. The co-evolution of dogs and humans and the unique, familial relationships people have developed with them suggest that they are owed special consideration of their needs and interests that is independent of their utility to humans. Not surprisingly, opposition to commercial breeding enterprises has increased dramatically in the past decade in the US and abroad, spawning a growing number of legislative initiatives aimed at regulating such operations, which are widely believed to harm dogs. Among the most significant ethical problems embedded in commercial dog breeding are the potential for insults to the human-dog bond, failure to duly consider and meet duties of care to dogs, including dogs' welfare needs and interests, and insufficient regulation of dog care standards. The shortage of published science on the actual conditions experienced by dogs in commercial breeding kennels complicates understanding of the nature and severity of problems as well as solutions. It is argued that despite the concerns associated with commercial dog breeding, abolishing the practice without identifying an ethically preferable alternative that meets demands could result in even worse consequences for dogs. Given this problem, commercial breeding could be ethically defensible under conditions that vastly reduce or eliminate potential for dog suffering, and with strict regulatory oversight of corresponding standards of care for dogs.
\end{abstract}




\section{Keywords}

commercial breeding - dogs - animal welfare - ethics

\section{Introduction}

As one of the earliest domesticated animal species (Clutton-Brock, 1995), the relationships between people and dogs around the world are diverse and ubiquitous. Archeological evidence suggests that humans and dogs have coexisted for thousands of years (Miklosi, 2014). Today dogs rank among the most popular pets people keep, particularly in western cultures (Archer, 1997; King et al., 2012). In the United States (US), the domestic dog is such a popular companion animal that over 60 million households reportedly keep one or more (American Pet Products Association, 2017). Equally high rates of dog ownership are reported in Australia and the United Kingdom, where over $60 \%$ and $50 \%$ of households respectively report keeping dogs (Goodwin et al., 2018). The popularity of dogs as companions is further evidenced by the substantial and ongoing increase in expenditures on pet-related products that has occurred in the past decade (Bir et al., 2016; APPA, 2017).

Although people's reasons for keeping dogs may vary, the benefits of humandog relationships for human physical, psycho-social well-being are well documented (Vormbrock, 1988; Cutt et al., 2007; Wells, 2007; Knight et al., 2008; Christian et al., 2012). Consistent with these findings, respondents to the American Pet Products Association National Pet Owner Survey (2017) who kept dogs reported that they derived happiness and emotional support from their pets, experienced stress relief and lower anxiety or depression, as well as health benefits that included lower blood pressure and increased exercise. Dogs likewise benefit from relationships with people; domestication is suggested to have enhanced their social and communication abilities, cooperative existence and hunting with each other and humans (Morey, 1994; Hare et al., 2002). It is also thought to have facilitated dogs' nutritional status (Axelsson et al., 2013), benefiting their reproductive success and longevity (Coppinger \& Coppinger, 2001). The impacts of the bonds between people and dogs undoubtedly impacts contemporary views of dogs and our perceived obligations toward them. As dog-human relationships continue to evolve, views on what we owe to dogs are changing accordingly.

An overwhelming number of Americans now think of dogs as family members (Holbrook \& Woodside, 2008; Bir et al., 2016), building on trends toward such views that have been documented since at least the 1980s (Cain, 1983; 
Stallones et al., 1988). Unsurprisingly, as the market for companion dogs grows along with familial characterizations of them, public concern for their welfare is escalating. This has culminated in fractious debates about how to meet the demand for companion dogs, while sustainably and ethically sourcing them. Commercial dog breeders currently help to supply US consumers with the purebred and 'designer' dogs they desire (Hurt et al., 2016; Bauer et al., 2017). In the US, dogs from such kennels are typically made available to consumers through sales in pet stores or via online retailers. However, the ethical issues embedded in high volume, commercial production of dogs are considerable, leading to skepticism about whether there can be any moral justification for such operations. The purported harms to dog welfare in commercial breeding operations, facilitated by thinking of and treating them as mere commodities, and inadequate regulation of dog care and welfare standards rank high among the most serious reported problems. Further, the venues that are supplied by commercial breeders enable such easy access to dogs, that it has been suggested that this facilitates impulse purchasing that may not result in best outcomes for dogs. In light of these concerns, I consider whether commercial dog breeding, in any form, can be ethically defended. In this paper, I do not defend any particular position on the moral justifiability of keeping or breeding dogs. Instead, I explore the ethical implications of commodification of dogs, public perceptions and behaviors relative to dog acquisition, and the roles these factors play in supporting commercial breeding. Next, I explore significant physical and behavioral well-being challenges that must be navigated within commercial (and other) breeding of dogs. I then review the implications of different approaches to regulating commercial dog breeding, arguing that attempts at wholesale bans on commercial breeding in absence of a suitable alternative to meet or curtail demands for dogs potentially do more to jeopardize than to improve dog welfare. Finally, I challenge the notion that commercial dog breeding is entirely indefensible, offering arguments for how such breeding conducted under specific conditions might help to ensure a sustainable supply of companion dogs, while reducing existing harms to them.

\section{2 \\ Commodification of Dogs: Implications for Their Welfare in Commercial Breeding Operations}

Animal welfare is increasingly described as a 'wicked problem' and a complex component of virtually all types of animal production (Whyte et al., 2012). Although the care and welfare of animals used for production of food is receiving significant media coverage in the US and abroad, analogous concerns 
about animal treatment extend to those used for other purposes, such as dogs, which today are used for research, teaching, therapeutic interventions, various types of work, sport/entertainment and companionship. Commercial breeding of dogs, often referred to in the US as 'puppy mill' breeding and in the United Kingdom and Australia as 'puppy farming', helps to meet public demand for dogs suitable for these various purposes. However, commercial dog breeding currently faces public scrutiny and sentiment not unlike that directed at intensive confinement farming of food animals. Although the ultimate purpose for which the animals are intended differs, many of the ethical and general welfare issues raised are similar. The latter include the extent to which the physical, behavioral and psychological needs of the animals can be met (Fraser et al., 1997; Broom, 1998; Webster, 2001) in the conditions in which they are raised, and the specific effects of genetics, housing, handling (quality of caretaker interactions) and behavioral management on the quality of life the dogs experience.

High volume, confinement production of dogs is even more emotionally laden in part because of the cultural connotations associated with human-dog interactions in western developed nations, and because people's positive relationships with companion animals may prime them to worry about animal welfare (Croney, 2011, 2014; McKendree et al., 2014). Given that over $48 \%$ of the US population owns dogs (APPA, 2017), commercial breeding, particularly under conditions that appear to do dogs harm, evokes strong reactions by the US public.

The commodification of dogs that is embedded in any discussion of highvolume commercial dog breeding muddies the waters in what is already an ethically troublesome enterprise. The act of bringing dogs into being solely to profit from their existence transforms them into commodities and is at odds with the uniquely familial relationships domestic dogs and people share today. According to Burgess-Jackson (1998), the mere act of forming a bond or relationship with a sentient being engenders a responsibility to care for its needs, and "there is a bond of mutual trust between dog and human that should not be breached". Hens (2009) adds that special responsibilities to dogs are generated by accepting them as family members, which include attending to their physical and emotional welfare and protecting the bonds of trust created between the human-dog dyad. Further, following Russow (2002), the animal with whom there is a human-animal bond is not regarded as a mere commodity nor valued solely for its utility (Croney, 2014). Clearly, one cannot hold views of dogs as friends and family and simultaneously advocate for their commodification without creating a fair amount of cognitive dissonance. It is therefore necessary to deliberate about whether dogs are owed special consideration 
beyond that given to other animals that are farmed or reared for human benefit. The idea that dogs are sentient beings is not a point of debate. The implications of their sentience, are more troublesome. Few who buy or breed dogs even on a small-scale appear to have trouble ascribing extrinsic value to them while simultaneously expressing views that are more in keeping with dogs as intrinsically valuable. It may be that dog buyers and breeders hold beliefs about animal-human relationships that facilitate contradictory or compartmentalized thought processes about dogs. Alternatively, their views may allow them to conclude that producing dogs (even under sub-par conditions) brings about better societal consequences than not breeding them at all. The latter line of thinking would be consistent with consequentialist theories which are based on the premise that an action is justified if it brings about the best consequences (Singer, 1983).

It is also plausible that it is the scale at which dog breeders operate rather than the actual commodification of dogs themselves that potentially creates ethical and psychological discomfort. Certainly issues of scale would help to explain skepticism about whether and to what extent there can be appropriate consideration of dogs' welfare interests (Bateson, 2010) and meaningful bonds between caretakers and individual dogs in high-volume breeding kennels.

It could be argued that outside of conceptions of animal rights, wherein rights are "trump cards" that preclude uses of animals that infringe on their rights (Regan, 1984), or Francione's (2007) suggestion that domestication is a form of slavery that is perpetuated by deliberate breeding, there is nothing inherently wrong with buying and selling dogs and puppies if they are bred, reared and cared for in ways that give due consideration to (and real effort toward) protection of their needs and interests. Commodification of dogs, however, especially on a large scale, may work against such consideration.

Animals' interests are central to their welfare. Aside from the biological 'fitness' benefits of passing on their genes, it is difficult to see how a coherent argument could be made that being reared solely to produce puppies for profit and then killed might be in a dog's interests. It is even more problematic for such an exercise to occur under conditions that appear to forego consideration of the notion that sentient animals (as dogs undoubtedly are) have a right not to be made to suffer (Singer, 1995; Garner, 2013). If such issues arise when small numbers of individuals are impacted, concerns increase exponentially when very large groups are involved. It is therefore reasonable to wonder if dog welfare can realistically be viewed as compatible with commercial production, especially because at high volume, attention to individual needs and interests likely presents an even greater challenge. In this regard, commercial dog breeding raises remarkably similar challenges to those encountered in debates 
about the ethics of farming livestock and poultry (Singer, 1983; Regan, 1984; Leneman, 1999; Buller \& Morris, 2003; Francione, 2010; Garner, 2013). As suggested by Francione (2007), commodification of dogs may therefore facilitate ways of thinking (or not thinking) about their interests, that may serve to undermine their welfare.

\section{$3 \quad$ Public Perceptions and Sourcing of Dogs}

The idea that dogs need greater protection, including from the unintended or unaddressed consequences of breeding without due consideration of their interests is increasingly apparent in public views on ethical sourcing of dogs. In the US and other western countries, there is a growing movement to promote adoption of dogs from animal shelters and rescues over purchasing them from dog breeders and other venues (Sinski, 2016). Public campaigns, such as the "adopt, don't shop" slogans that are currently popular appear to promote adoption of dogs as a moral imperative for those seeking canine companions (Bir et al., 2017). As evidence of the effectiveness of such messages, respondents to a survey of 670 US households that reported keeping dogs as pets noted that the most common reason dogs were acquired from a shelter was because "it was the right thing to do" (Bir et al., 2016). However, in the same study, the majority of respondents expressed a desire to have a choice of sources from which to acquire dogs (Bir et al., 2016). Similarly, Bir et al. (2017) found that adoption of dogs was prioritized as the most ethical means of acquiring them by a large majority of respondents, even though sub-groups within the study population were receptive to sourcing dogs from a variety of other sources.

Despite the desire for diverse sources from which to obtain dogs, public perceptions of commercial breeding operations appear to be highly negative (Bateson, 2010; McMillan, 2011; Bir, 2016). For many concerned parties, this type of dog breeding is perceived to exacerbate existing welfare problems associated with pet overpopulation problems in shelters and rescues, thus contributing to already high rates of animal relinquishment, abandonment and euthanasia and the draining of financial resources of humane organizations. Yet, there is no universal agreement among experts in companion animal population dynamics that there is currently a dog overpopulation problem in the US. And, although far too many dogs are euthanized annually, existing data suggests that behavioral problems are the primary cause of dog relinquishment to shelters (Scarlett et al., 1999; Scarlett et al., 2002; Patronek et al., 1996; Kwan \& Bain, 2013). Moreover, the finding that only small percentages of shelters surveyed held purebred dogs (NAIA, 2015) contradicts the idea that 
production by commercial breeders contributes excessively to the numbers of dogs needing homes. It is plausible that today, the problem of unnecessary euthanization of dogs in shelters is due more to having too many unwanted companion dogs than to having more dogs than there are available homes (Bauer et al., 2016).

A more compelling argument against commercial dog breeding is that dogs lingering in shelters and rescues might be adopted but for the volume of animals produced by commercial (and other) dog breeders. A few major problems confound this argument, however. First, it is uncertain that shelters, rescues and small-scale breeders could meet current demands for dogs given existing models (Patronek \& Rowan, 1995) for calculating the supply needed for prospective pet owners. Second, shelter and rescue dogs must originate somewhere; for these avenues of dog sourcing to exist, dogs must be bred at some level. Putting aside the question of whether dogs should be bred at all, those seeking dogs typically desire specific characteristics. Appearance is among the most consistently cited determinant of the decision to purchase or adopt a dog (Weiss et al., 2012; Brown et al., 2013), while behavior and temperament (Posage et al., 1998; Weiss et al., 2012; Protopopova \& Wynne, 2014; Protopopova et al., 2014), size, breed, age, coat color, health and purebred status are high on people's lists of preferred characteristics (Posage et al., 1998; Lepper et al., 2002, Diesel et al., 2007; Svoboda and Hoffman, 2015). Clearly, breeders are uniquely positioned to meet such needs and may be in a better position to do so in the volume needed to match supply than are shelters. Further, some prospective owners may desire dogs whose entire histories are known to them or those they can raise from puppies, both of which may be difficult to find in shelters. It should also be noted that while commercial breeders may be perceived as 'bad actors' for breeding dogs in high volume without the guarantee of appropriate adoptive homes, or maintaining dogs in a manner vastly different from the small-scale breeder, they could not survive, much less thrive, but for high public demand for purebred and 'designer' dogs. Additionally, relinquishment of dogs is a reflection of failed human-animal bonds that cannot be blamed entirely on high volume breeders. The conditions under which dogs are offered to prospective owners and the extent to which these support responsible, informed consumer behavior must also be scrutinized. Although Patronek et al. (1997) found no association between level of planning prior to acquiring a dog and relinquishment (Patronek et al., 1997), impulsive purchases of dogs, facilitated by affordable prices, high inventory, convenient venues (e.g., 'click to purchase' options) and absent or minimal counseling are hardly conducive to the development of strong dog-owner bonds and positive consequences for dogs. Owner education, planning, expectations, and values relative to responsible 
sourcing and maintenance of pets, must therefore be acknowledged as potential contributors to companion dog welfare outcomes.

It must also be considered that while it might be tempting to promote the idea of eliminating commercial dog breeders entirely in favor of relying only on small scale breeders to provide dogs for purchase, this may have unintended consequences (detailed later). One of these is that high demand for dogs combined with reduced supply would likely drive up costs of dog procurement from all sources. Consequently, access to dog ownership could become substantially more constrained by economics. In light of the previously discussed health benefits of the dog-human relationship, it could be argued that eliminating commercial breeders might indirectly exacerbate human health and quality of life disparities that already exist as a function of socioeconomic status. Such an argument in itself is not sufficient to justify commercial breeding. The infringements on dogs' interests and ethics of care engendered by the doghuman bond should be weighed at least as heavily as the human health and happiness benefits that might be derived from producing dogs in high volume. Commercial Dog Breeding

While the term, 'animal welfare,' may be interpreted in myriad ways by different people, it fundamentally pertains to value-laden notions about animal quality of life. All animal welfare concerns are rooted in the belief that we have obligations to maintain an acceptable standard of care and well-being for the animals we choose to keep and utilize for different purposes. Achieving consensus on such standards, however, presents a considerable challenge. For some people, animal welfare is "just good husbandry"; it simply entails providing for animals' basic needs for food, water, shelter and veterinary care. However, it is increasingly acknowledged that for an animal to do well, both its physical and behavioral health must be addressed (Broom, 1988; Fraser et al., 1997). An earlier, and widely discussed conception of animal welfare was couched in terms of "the five freedoms" outlined by the Brambell Committee in the United Kingdom in 1965 (Webster, 2001), which have now become the basis for many animal welfare initiatives in developed western nations. Building on the ideal states described by the Five Freedoms, Fraser et al. (1997) proposed that animal welfare could be thought of as three different but interrelated conceptions. First, animals should function physically, e.g., a dog must be in good body condition and free from disease and injury; second, an animal should feel well (e.g., a dog should experience positive mental states such as pleasure, 
and avoid negative states like pain, frustration, and fear); and third, animals should be able to live naturally, that is, that the dog should be able to express behaviors intrinsic to her nature and live in a manner that reasonably accommodates her natural social structure and physical environment.

In light of these ideas, life in a commercial breeding kennel is potentially challenging to dog welfare, although the high variation that exists in kennel design and management likely results in differing levels of success in meeting the challenges. The nature of and extent to which dogs may suffer in such kennels therefore directly relates to their management. One of the most commonly reported complaints is the maintenance of dogs in squalid conditions that compromise their physical health and comfort (Bateson, 2009; Hurt, 2016). Other major breeding kennel welfare challenges include, but are not limited to: meeting dogs' behavioral needs (McMillan et al., 2011), such as their need for socialization, exercise and enrichment, the quality of housing and nutrition, and the frequency of preventive and therapeutic veterinary care. In addition, breeding frequencies, ages, selection criteria, and litter numbers require scrutiny. The disposal of dogs at the end of their breeding careers raises additional ethical, scientific, and practical challenges. Older breeding dogs at the end of their productive lives face risks associated with 'convenience euthanasia' which may involve questionable methods, or disposal in other ways that potentially jeopardize their welfare, such as long transport distances and holding times when sold at auctions. Finally, breeding of dogs without guaranteed, suitable homes for their puppies in itself raises questions about the risks to puppy welfare and further failure to consider dogs' interests. What fate, for instance, befalls the puppy? Overall, there are three areas that are particularly important to evaluate in the context of duties of care owed to dogs in commercial kennels: 1) the quality of the environment in which dogs are kept, 2) genetic selection and reproductive management of dogs, and 3) attention to behavioral well-being.

\subsection{Quality of the Housing Environment}

Both the behavioral and physical health aspects of dog welfare are influenced by the environment. In particular, the quality and complexity of the rearing environment exert profound influences on dog development and behavior (Scott \& Fuller, 1965). Ensuring the quality of the kennel environment can pose a challenge even in small kennels that maintain only one breed of dogs. Doing so for high numbers of dogs of various breeds as are often found in commercial kennels is even trickier. For example, keeping dogs at comfortable ambient temperatures can be difficult when the thermoneutral zone is $20^{\circ} \mathrm{C}\left(68^{\circ} \mathrm{F}\right)$ to $30^{\circ} \mathrm{C}\left(86^{\circ} \mathrm{F}\right)(\mathrm{NRC}, 2006)$ and a kennel must simultaneously meet the different thermal comfort needs of multiple breeds, such as huskies (NRC, 2011), for 
whom the lower critical temperature is $0^{\circ} \mathrm{C}\left(3^{\circ}{ }^{\circ} \mathrm{F}\right)$. A commercial kennel must meet these needs while also addressing variations necessary to accommodate age, size and physical state (e.g., pregnancy or illness). Breeders also have the difficult task of providing at least the amount of space required by law and determining the types of spaces dogs need and prefer, while adjusting as appropriate for the age, breed, size, gender, or physical status of the dog, and as a function of the type of accommodations and resources provided (Coppinger \& Zuccotti, 1999). Commercial breeders must balance these needs for numerous dogs, including those of different breeds if they keep multiple breeds.

\subsection{Genetic Selection and Reproductive Management}

The welfare issues associated with pure-breeding of dogs in general are well detailed (see, for example, Rooney, 2009). While all of these, such as overly close inbreeding or breeding of offspring known to carry serious heritable problems, pertain to commercial dog breeding, high volume breeding requires an additional level of scrutiny of the risks to dogs and their welfare interests, due to potential amplification of harm. Selection criteria for breeding animals and their reproductive management in commercial kennels are key considerations here. Breeding of dogs without due consideration for the criteria on which they are selected to reproduce (beyond aesthetics) is neither in their interests, nor ultimately that of their human families and communities. For example, selection for extreme breed characteristics that result in debilitating or disabling anatomical or physiological conditions (e.g., bitches that cannot whelp without surgical intervention-Rooney, 2009) can be viewed as violating the dog's telos as well as its integrity. As described by Rollin (1993) telos refers to the animal's genetically encoded 'nature,' which reflects the function for which it was intended. Repeated breeding of bitches whose conformations are known to be so extreme as to require multiple cesarean sections compounds the existing ethical and welfare issues and is even less morally justifiable.

Further, because a dog's physical and behavioral characteristics, including temperament are largely determined by their genetics, careful attention to genetic selection for comprehensively healthy animals is essential to produce lifelong companions that meet the expectations of their prospective families (Bateson, 2009). Failure to ensure that these criteria are met can potentially results in unpleasant states such as boredom, frustration and chronic arousal/ distress (Fraser et al., 1997). Studies of the life-long physical and behavioral impairments of animals experiencing distress in utero and improper or undue neonatal stress (Meaney, 2010) provides strong impetus to avoid management practices that result in maternal stress in breeding bitches and subsequent negative impacts on puppies due to chronic activation of the hypothalamic 
pituitary adrenal axis (Francis et al., 2002; Francis \& Meaney, 1999). Impaired learning, chronic arousal and increased sensitivity to stress-inducing stimuli that manifests in fearfulness and aggression to people and other animals are likely to be poorly tolerated by dog owners. Other problematic behaviors that may be worsened by improper genetic selection and environmental management of commercially bred dogs include excessive vocalization, house soiling, and destructive behaviors. Dogs that are not carefully genetically selected and managed are therefore at heightened risk for mistreatment, relinquishment, abandonment, or euthanasia.

In addition, it is imperative to establish appropriate ages for breeding animals, and the number and quality of litters that can reasonably be expected to be produced in a given time frame without undue physical distress and deterioration to the breeding animals and their offspring. Appropriate and timely intervention schemes must also be derived that better reflect current scientific discoveries in canine reproduction. It should also be noted that these considerations are relevant and perhaps even more significant when dogs are bred by amateur owners or "backyard" breeders, especially when the parent dogs are not screened for genetic disorders or genetic relatedness. Such matings pose risks for the offspring, especially relative to their health and fitness for the purpose for which they are bred.

\subsection{Behavioral Well-Being}

The selection and management of breeding dogs for behavioral soundness is particularly salient to assessments of their overall welfare and moral justification of high volume dog breeding. Anecdotal (Bir et al., 2017) and owner reports of physically and behaviorally unwell puppies sold in pet stores that are presumed to come from commercial dog breeders abound (McMillan et al., 2011, 2013). However, even the published studies of owner reports of canine behavior are based on indirect inferences about dogs from commercial breeding kennels (McMillan et al., 2011, 2013). Also, since these studies have often been based on reports of animals rehomed following seizures by authorities, the populations included are likely skewed toward the most compromised animals given that such seizures typically occur when dogs are kept in conditions that fall far short of minimum care standards. Thus, there are significant deficits in our knowledge of the actual conditions and welfare states experienced by dogs and puppies from more broadly representative commercial breeding facilities.

Nonetheless, since the leading cause of pet animal relinquishment is behavioral problems, it is ethically problematic to breed dogs at risk for behavioral abnormalities given that the intention is for these animals is to live harmoniously with people for the duration of their lives. Further, given the ethology 
of the dog, there is high propensity for suffering if those maintained for commercial breeding do not receive adequate attention to their needs for enrichment, normal social interactions with conspecifics, positive human-animal interactions, appropriate socialization and sufficient exercise. For example, the importance of socializing dogs early in life has been well outlined (see for example, Scott \& Marston, 1950; Serpell \& Jagoe, 1995). Yet, it is suggested that socialization of adult dogs and puppies is either absent or minimal in commercial kennels, potentially causing direct harm to the dogs, and indirect harm to their prospective owners and communities.

Similarly, high levels of fear have been reported in breeding bitches (McMillan et al., 2011). As noted earlier, chronic experience of fear and stress poses significant physical and behavioral risks to the animals, their off-spring, and to adoption and rehoming outcomes. The importance of maternal genetic, behavioral, and physical health on the well-being of puppies is well established (Scott \& Fuller, 1965). Maternal stress can negatively impact puppies' immune status, including antibody absorption (Gillette \& Filkins, 1966). Dam stress resulting from poor genetic selection or deficient environments (such as those lacking enrichment or the opportunity to exercise) may also impact maternal care. Adult dogs from bitches that provided higher levels of maternal care were less anxious later in life (Tiira \& Lohi, 2015), less fearful of novelty, and performed better on spatial learning and memory tasks (Foyer et al., 2013, 2016). They also were more social and more likely to explore and interact with their physical environments than pups from lower care-providing dams (Czerwinski et al., 2016; Foyer et al., 2013, 2016).

Because published studies of canine behavior and welfare in commercial breeding kennels are almost entirely absent, an outstanding question is whether and to what extent dogs' behavioral needs can be met in such kennels, especially as a function of the scale of the operation. Keeping in mind that commercial breeding kennel management, housing designs, and dog numbers may all vary widely, any assessment of their suitability for dogs should incorporate whether they permit dogs to live according to their telos. Rearing an animal in a manner that permits meeting of her telos, according to Rollin (1993, 2007), requires "meeting of those needs and interests that matter to the animal and affect its feelings by virtue of its biological and psychological nature". Thwarting of behaviors that are specific to the nature of the dog, and especially those that dogs are highly motivated to perform, such as engaging in social interactions with each other and human caretakers would violate their telos, and consequently impinge on their welfare. Rearing dogs in kennels designed in a manner that significantly and continuously restricts their abilities to engage in behaviors that are both natural to their species and preferred may generate 
frustration and other negative affective states that undermine their psychological and emotional well-being (Fraser, 2009). Because such unpleasant states typically elicit physiological stress responses in an attempt to cope, the dog's overall biological 'fitness' may also be negatively impacted (Broom \& Johnson, 1993; von Borell, 1995; Moberg, 2000). In short, such conditions would predispose dogs to suffering, and should be minimized, if not eliminated.

Consideration of the dog's telos in concert with its broader welfare needs must therefore be integral to evaluations of its capacity to cope successfully with the environmental and production demands of the commercial breeding kennel.

\section{5}

\section{Regulation of Commercial Dog Breeders}

In the US, although licensed commercial breeders, unlike puppy mills, are regulated and inspected for compliance with applicable federal and state standards of care, there is still significant concern about the welfare of dogs and puppies in commercial breeding facilities (Bir et al., 2017; Hurt, 2016). In the past decade, attempts to regulate US and European commercial dog breeding operations have increased dramatically. While the US Animal Welfare Act has mandated standards for the care of dogs, cats and other animals bred for commercial sale since 1966, some exemptions exist. For example, sales where the buyer, seller, and dog are in the same physical space are exempt from licensing requirements as are breeders who have four or fewer adult females and only sell the puppies produced on their property. Additionally, because breeders must initiate the licensing process, if a breeder does not apply for a license there will be no federal oversight until or unless the regulated activity becomes public (USDA Animal and Plant Health Inspection Service, 2018). This increases the risks that animals can be maintained in sub-par conditions in puppy mills with little protection other than that offered by state anti-cruelty statutes. However, compounding this issue is the problem of defining such an operation in the first place.

There is little consensus on whether a 'puppy mill' is created as a function of the number of animals maintained for breeding, the total number of animals kept, the number of litters produced annually, or as a function of the living conditions, management and quality of care provided to the animals. There is also no clear way to distinguish a commercial breeder from a 'puppy mill' based on current definitions of these terms, which are often used interchangeably. In 2008, the state of Virginia's House Bill 538 defined a commercial 
breeder as "a person who, during any 12-month period, maintains 30 or more adult female dogs for the primary purpose of the sale of their offspring as companion animals" (VA HB 538, 2008). The state of Indiana defines a commercial dog breeder as someone who "maintains more than 20 unaltered females 12 months of age or older" (воАн, 2018). Moreover, US state standards for the humane care of dogs categorized as coming from a commercial breeding operation vary on requirements for housing, sanitation, nutrition and veterinary care. Few, if any, appear to mandate conditions relative to behavioral wellbeing of the animals.

Because of the reported deficits in the selection, rearing and management practices purported to be used in commercial dog breeding kennels, societal concerns about such operations have been heightened (Osborne, 2008). Not surprisingly, this has led to polarized public discussions and various attempts to regulate or entirely eliminate commercial dog breeding. Recently, such efforts have extended toward entirely banning the sale of dogs and other pets in retail pet stores (Osborne, 2008; JAVMA News, 2017). Theoretically, banning stores from selling dogs and puppies, which are typically supplied by commercial breeding kennels, reduces opportunities for such operations to thrive and likely drives commercial breeders out of business. However, while pet store sale bans appear to offer a solution to dog welfare problems, this course of action by itself is highly problematic. First, these bans do nothing to address the welfare of adult dogs on-site at breeding kennels. Rather, they potentially create risks for the existing breeding stock if commercial breeders are consequently unable to market their puppies, and thus, off-set the costs of maintaining the breeding adults. Further, eliminating (minimally) regulated suppliers of dogs does not address demand; it merely removes a sales venue that is accessible and relatively transparent to the public. Second, demand for purebred dogs that cannot realistically be met by small-scale breeders, shelters or rescue groups in the US generates multiple additional risks. It potentially creates a black market for dogs and increases the likelihood that commercial breeders will simply seek out ways to breed and distribute dogs that are even less wellregulated. It also increases the possibility that others, including totally unregulated backyard breeders, will attempt to fill gaps in supply of dogs created by displacing regulated commercial breeders. The explosion of online retailers of purebred dogs (Voris et al., 2011) suggests that this dynamic is already occurring in the US and elsewhere. Likewise, in the United Kingdom, increased discoveries of illegal puppy imports have been reported following regulatory changes that permit unscrupulous dog breeders to creatively meet market demand for dogs (Gidda, 2018). There is also risk that those attempting to procure dogs for 
customers may resort to importing animals, including from other countries, as is already occurring. Importation from locations where dogs may be exposed or pre-disposed to diseases uncommon to or eradicated in the US potentially poses significant health risks to US dog populations (McQuiston et al., 2008). In addition, if the conditions under which such imported dogs are bred and reared are as problematic as, or worse than those currently being criticized in the US, then not only would existing welfare issues remain unaddressed, but instead new markets would be created for dogs produced under conditions that are detrimental to their well-being. Troublingly, this phenomenon appears to be emerging in the US (Becker, 2011).

Strengthening existing state or federal mandates pertaining to commercial dog breeding care standards is an alternative to banning retail pet store sales of dogs originating from commercial kennels. While such laws might address several of the existing welfare issues, the extent to which they may be able to comprehensively address welfare is limited given that to realistically attain compliance they must be written as minimum standards. Already, there is criticism about the high variability in existing US state laws relative to commercial breeding standards, given that many of these either overlook or do not fully address important components of dog well-being, such as genetics and behavior. Several such laws focus only on the most basic aspects of dog health, and on provision of minimum care requirements (e.g., food, water, shelter, veterinary care, and sanitation of facilities). Further, enforcement of existing US laws is already financially constrained.

Complicating matters, there is very limited scientific evidence on which to base changes to legislated or voluntary requirements for dog care and welfare in commercial breeding kennels. As previously noted, no systematic studies have been conducted on the welfare (state of being) of dogs on-site in commercial breeding kennels that might provide insight into the nature and etiology of welfare problems reported about puppies and dogs thought to originate from them (McMillan, 2017). Further, recent findings from studies conducted at commercial kennels conflict with some of those reported by McMillan (2011, 2013). For example, one study assessing dogs' physical welfare and cleanliness in licensed commercial breeding facilities in Indiana found no significant problems in these areas (Hurt, 2016). In addition, Bauer et al. (2017) found high proportions of affiliative behaviors in dogs in commercial breeding kennels. These inconsistencies give credence to the idea that with appropriate management, diligent commercial dog breeders may be able to meet dogs' welfare needs. In the absence of more robust science to inform moral deliberation about the welfare effects of keeping dogs in high volume kennels, the much debated precautionary principle (Kriebel et al., 2001) should be adopted. In 
short, steps should be taken to protect dogs against potential harms in commercial kennels, even if causal factors are currently uncertain.

\section{Can Commercial Dog Breeding Occur in an Ethically Responsible Manner?}

Assuming that all claims of harm (such as failure to meet duties of care to dogs or to uphold the trust engendered by the human-dog bond) levelled against commercial dog breeding were able to be verified and found to be representative of the industry, then certainly, this type of breeding enterprise could not be morally defended. However, even if only some of the welfare problems identified were proven, the practice of commercial dog breeding as is could still not be defended. From a rights-based perspective, the interests of dogs as sentient beings cannot be overridden regardless as to the benefits to people. Looked at from a utilitarian perspective, maintaining dogs under conditions that cause them suffering, including denying them opportunities to live in accordance with their telos and also depriving them of experiencing pleasurable states leads to the same conclusion-such use is not justifiable.

Keeping in mind both the lack of scientific knowledge about commercial dog breeding and reported concerns, there are good reasons to be skeptical that such operations can be morally justified. However, given the high demand for dogs, including purebreds, that is projected to increase, the role that regulated commercial breeders play in meeting such demands, and the risks of unintended consequences (e.g., black markets for dogs) if such breeding was abolished without identifying a responsible alternative, a case can be made in support of high volume kennels. The strength of that case rests upon whether the interests of dogs can be respected and to what degree, and whether the duties of care owed to them can reasonably be met in commercial breeding kennels.

Perhaps the most defensible position for commercial dog breeding is to argue that it theoretically could be justified if significantly higher standards of care that better protected dog welfare could be ensured. If indeed dogs have a right against suffering, then that suffering should be attenuated, and ideally, eliminated entirely. More stringent, enforced regulation of breeding dog care standards would be needed to meet this goal. In addition, it would be essential to increase transparency about breeding practices and improve consumer education so as to promote informed dog sourcing decisions and responsible dog ownership. To gauge the practicality of this approach, it would first be essential to conduct studies that directly examine dog behavior and welfare at 
commercial breeding operations. This would permit causal inferences needed to make informed recommendations to ensure that commercial dog breeding practices protect dog welfare.

It is ironic that the human-dog bond is so highly valued in western developed nations that people will (knowingly and unknowingly) tolerate various types and degrees of harm to dogs in order to perpetuate their existence. Here, Francione's (2007) statement that domesticated animals "remain forever in a netherworld of vulnerability" rings true. However, responsibility for such a one-sided bargain cannot be solely attributed to commercial dog breeders. Given that eliminating commercial breeding while human demand for dog companionship remains high might result in even worse consequences for dogs, commercial breeding, conducted with greater oversight of dog welfare, while perhaps not the ethically preferable solution, is ethically defensible.

\section{Acknowledgements}

The author gratefully acknowledges the contributions of Gary Varner, Traci Shreyer, Judith Stella, and Hannah Flint who provided editorial help and useful comments that were incorporated into the paper.

\section{References}

American Pet Products Association (2017). 2017-2018 National Pet Owners Survey. Available online: http://www.americanpetproducts.org/press_industrytrends.asp [Accessed March 2, 2018].

Archer, J. (1997). "Why do people love their pets?" Evolution and Human Behavior, 18, 237-259.

Axelsson, E., Ratnakumar, A., Arendt, M.L, Maqbool, K., Webster, M.T., Perloski, M., Liberg, O., Arnemo, J.M., Hedhammar, A., \& Lindblad-Toh, K. (2013). "The genomic signature of dog domestication reveals adaptation to a starch-rich diet". Nature, 495, $360-364$.

Bateson, P. (2010). Independent Inquiry into Dog Breeding. Cambridge: University of Cambridge.

Bauer, A., Beck, A., Stella, J., \& Croney, C. (2016). Overpopulation or Too Many Unwanted Pets? Perspective on Concepts and Management Approaches. Available online: https://www.extension.purdue.edu/extmedia/VA/VA-14-W.pdf [Accessed March 21, 2018]. 
Bauer, A., Jordan, M., Colon, M., Shreyer, T., \& Croney, C. (2017). "Evaluating FIDO: developing and pilot testing the Field Instantaneous Dog Observation tool". Pet Behaviour Science, 4, 1-15.

Becker, K. (2011). The Accidental Consequence of Cracking Down on Puppy Mills. Healthy Pets. Available online: https://healthypets.mercola.com/sites/healthypets/ archive/2011/01/o6/avoiding-buying-illegally-imported-pet-dogs.aspx [Accessed March 1, 2018].

Bir, C., Croney, C., \& Widmar, N.O. (2016). Public perceptions of dog welfare, sourcing and breeding regulation. Purdue University. Available online: https:/www.vet. purdue.edu/CAWS/files/documents/20160602-public-perceptions-ofdog-welfaresourcing-and-breeding-regulation.pdf [Accessed March 6, 2017].

Bir, C., Widmar, N., \& Croney, C. (2017). "Stated preferences for dog characteristics and sources of acquisition". Animals, 7:8, 59 .

в ОАН (2018). Commercial Dog Breeder \& Broker. Indiana State Board of Animal Health. Available online: https://www.in.gov/boah/2549.htm [Accessed March 1, 2018].

Broom, D.M. (1988). "The scientific assessment of animal welfare". Applied Animal Behaviour Science, 20, 5-19.

Broom, D.M., \& Johnson, K.G. (1993). Stress and Animal Welfare. London: Chapman \& Hall.

Buller, H., \& Morris, C. (2003). "Farm animal welfare: a new repertoire of nature-society relations or modernism re-embedded?” Sociologia Ruralis, 43:3, 216-237.

Burgess-Jackson, K. (1998). “Doing right by our animal companions?” The Journal of Ethics, 2, 159-185.

Cain, A. (1983). "A study of pets in the family system". In: A. Katcher \& A. Beck, (eds). New Perspectives on Our Lives with Companion Animals. Philadelphia: University of Philadelphia Press, 72-81.

Christian, H.E., Westgarth, C., Bauman, A., Richards, E.A., Rhodes, R., \& Evenson, K.R. (2012). "Dog ownership and physical activity: a review of the evidence". Journal of Physical Activity and Health, 10:5, 750-759.

Clutton-Brock, J. (1995). "Origins of the dog: domestication and early history". In: J.A. Serpell (ed.), The Domestic Dog: Its Evolution, Behaviour and Interactions with People. Cambridge: Cambridge University Press, 7-20.

Coppinger, R. \& Coppinger, L. (2001). Dogs: A Startling New Understanding of Canine Origin, Behavior and Evolution. New York: Scribner.

Coppinger, R., \& Zuccotti, J. (1999). "Kennel enrichment: exercise and socialization of dogs". Journal of Applied Animal Welfare Science, 2, 281-296.

Croney, C. (2014). "Bonding with commodities: social constructions and implications of human-animal relationships in contemporary livestock production". Animal Frontiers, 4:3, 59-64. 
Cutt, H., Giles-Corti, B., Knuiman, M., \& Burke, V. (2007). "Dog ownership, health and physical activity: a critical review of literature”. Health and Place, 13, 261-272.

Czerwinski, V.H., Smith, B.P., Hynd, P.I., \& Hazel, S.J. (2016). "The influence of maternal care on stress-related behaviors in domestic dogs: what can we learn from the rodent literature?" Journal of Veterinary Behavior: Clinical Applications and Research, 14, 52-59.

Diesel, G., Pfeiffer, D.U., \& Brodbelt, D. (2008). "Factors affecting the success of rehoming dogs in the UK during 2005". Preventive Veterinary Medicine, 84, 228-241.

Foyer, E., Wilsson, E., Wright, D., \& Jensen, P. (2013). "Early experiences modulate stress coping in a population of German shepherd dogs". Applied Animal Behaviour Science, 146:1-4, 79-87.

Foyer, P., Wilsson, E., \& Jensen, P. (2016). "Levels of maternal care in dogs affect adult offspring temperament”. Scientific Reports, 13:6, 19253.

Francione, G. (2007). Animal Rights and Domesticated Nonhumans. Available online: http://www.abolitionistapproach.com/animal-rights-and-domesticated-nonhumans [Accessed March 6, 2018].

Francione, G.L. (2010). "Animal welfare and the moral value of nonhuman animals". Law, Culture and the Humanities, 6:1, 24-36.

Francis, D., \& Meaney, M. (1999). "Maternal care and the development of stress response". Current Opinions in Neurobiology, 9, 128-134.

Francis, D.D., Diorio, J., Plotsky, P.M., \& Meaney, M.M. (2002). "Environmental enrichment reverses the effects of maternal separation on stress reactivity". Journal of Neuroscience, 22:18, 7840-7843.

Fraser, D. (2009). "Assessing animal welfare: different philosophies, different scientific approaches". Zoo Biology, 28, 507-518.

Fraser, D., Weary, D.M., Pajor, E.A., \& Milligan, B.N. (1997). "A scientific conception of animal welfare that reflects ethical concerns". Animal Welfare, 6: 187-205.

Garner, R. (2013). A Theory of Justice for Animals. Oxford: Oxford University Press.

Gidda, M. (2018). The latest illegal business in the U.K. is dog smuggling. Newsweek January 16, 2018. Available online: http://www.newsweek.com/2018/01/26/illegal -business-uk-dog-smuggling-781508.html [Accessed March 1, 2018].

Gillette, D., \& Filkins, M. (1966). "Factors affecting antibody transfer in the newborn puppy”. American Journal of Physiology, 210:2, 419-422.

Goodwin, K., Rand, J., Morton, J., Uthappa, V., \& Walduck, R. (2018). "Email reminders increase the frequency that pet owners update their microchip information". Animals, 8:2, 20.

Hare, B., Brown, M., Williamsson, C., \& Tomasello, M. (2002). "The domestication of social cognition in the dog". Science, 298, 1634-1636.

Hens, K. (2009). "Ethical responsibilities towards dogs: an inquiry into the dog-human relationship". Journal of Agricultural and Environmental Ethics, 22, 3-14. 
Holbrook, M.B., \& Woodside, A.G. (2008). “Animal companions, consumption experiences, and the marketing of pets: transcending boundaries in the animal-human distinction". Journal of Business Research, 61:5, 377-381.

Hurt, M.J. (2016). Evaluating the Physical Welfare of Dogs in Commercial Breeding Facilities in the United States (unpublished master's thesis). West Lafayette, IN: Purdue University.

JAVMA News (2017). California bans retail sale of dogs, cats, rabbits. JAVMA News, November 15, 2017. Available online: https://www.avma.org/News/JAVMANews/ Pages/171201e.aspx [Accessed February 21, 2018].

King, T, Marston, L.C., \& Bennett, P.C. (2012). "Breeding dogs for beauty and behaviour: Why scientists need to do more to develop valid and reliable behaviour assessments for dogs kept as companions". Applied Animal Behaviour Science, 137, 1-12.

Knight, S., \& Edwards, V. (2008). "In the company of wolves: the physical, social, and psychological benefits of dog ownership". Journal of Aging and Health, 20, 437-455.

Kriebel, D., Tickner, J., Epstein, P., Lemons, J., Levins, R., Loechier, E.L, Quinn, M., Rudel, R., Schettler, T., \& Stoto, M. (2001). "The precautionary principle in environmental science". Environmental Health Perspectives, 109, 871-876.

Kwan, J.Y., \& Bain, M.J. (2013). "Owner attachment and problem behaviors related to relinquishment and training techniques of dogs". Journal of Applied Animal Welfare Science, 16:2, 168-183.

Leneman, L. (1999). "No animal food: the road to veganism in Britain, 1909-1944". Society \& Animals, 7:3, 219-228.

Lepper, M., Kass, P.H., \& Hart, L.A. (2002). "Prediction of adoption versus euthanasia among dogs and cats in a California animal shelter". Journal of Applied Animal Welfare Science, 5, 29-42.

McKendree, M.G.S., Croney, C.C., \& Widmar, N.J.O. (2014). "Effects of demographic factors and information sources on United States consumer perceptions of animal welfare". Journal of Animal Science, 92:7, 3161-3173.

McMillan, F.D. (2017). "Behavioral and psychological outcomes for dogs sold as puppies through pet stores and/or born in commercial breeding establishments: current knowledge and putative causes". Journal of Veterinary Behavior, 19, 14-26.

McMillan, F.D., Duffy, D.L., \& Serpell, J.A. (2011). "Mental health of dogs formerly used as 'breeding stock' in commercial breeding establishments". Applied Animal Behaviour Science, 135:1, 86-94.

McMillan, F.D., Serpell, J.A., Duffy, D.L., Masaoud, E., \& Dohoo, I.R. (2013). “Differences in behavioral characteristics between dogs obtained as puppies from pet stores and those obtained from noncommercial breeders". Journal of the American Veterinary Medical Association, 242:10, 1359-1363. 
McQuiston, J.H., Wilson, T., Harris, S., Bacon, R.M., Shapiro, S., Trevino, I., Sinclair, J., Galland, G., \& Marano, N. (2008). "Importation of dogs into the United States: risks from rabies and other zoonotic diseases". Zoonoses Public Health, 55:8-10, 421-426.

Meaney, M. (2010). "Epigenetics and the biological definition of gene X environment interactions". Child Development, 81:1, 41-79.

Miklosi, A., (2014). Dog Behaviour, Evolution and Cognition. Oxford: Oxford University Press.

Moberg, G.P. (2000). "Biological response to stress: implications for animal welfare". In: G.P. Moberg \& J.A. Mench (eds), The Biology of Animal Stress. Wallingford: CAB I Publishing, 123-146.

Morey, D.F. (1994). "The early evolution of the domestic dog". American Scientist, 82, 336-347.

National Animal Interest Alliance (NAIA) (2016). Survey of Shelter Dog Composition: Mutts vs. Purebreds. Available online: http://www.shelterproject.naiaonline.org/ purebred/ [Accessed January 29, 2018].

National Research Council (2006). Nutrient Requirements of Dogs and Cats. Washington DC: National Academies Press.

National Research Council (2011). Guide for the Care and Use of Laboratory Animals, Eighth edition. Washington DC: National Academies Press.

Osborne, M. (2008). "Revised state law goes after puppy mills". Journal of the American Veterinary Medical Association, 233:10, 1514, 1516-1517.

Patronek, G.J., \& Rowan, A.N. (1995). "Determining dog and cat numbers and population dynamics". Anthrozoös, 7, 199-205.

Patronek, G.J., Glickman, L.T., Beck, A.M., McCabe, G.P., \& Ecker, C. (1996). "Risk factors for relinquishment of dogs to an animal shelter". Journal of the American Veterinary Medical Association, 209:3, 572-581.

Posage, J.M., Bartlett, P.C., \& Thomas, D.K. (1998). "Determining factors for successful adoption of dogs from an animal shelter". Journal of the American Veterinary Medical Association, 213, 478-482.

Protopopova, A., \& Wynne, C.D.L. (2014). "Adopter-dog interactions at the shelter: behavioral and contextual predictors of adoption". Applied Animal Behaviour Science, 157, 109-116.

Regan, T. (1984). The Case for Animal Rights. London: Routledge.

Rollin, B.E. (1993). "Animal welfare, science, and value". Journal of Agricultural and Environmental Ethics, 6:Supplement 2, 44-50.

Rollin, B.E. (2007). "Cultural variation, animal welfare and telos". Animal Welfare, 16:S, 129-133.

Rooney, N.J. (2009). "The welfare of pedigree dogs: cause for concern". Journal of Veterinary Behavior, 4, 180-186. 
Russow, L.M. (2002). "Ethical implications of the human-animal bond in the laboratory". ILAR Journal, 43, 33-37.

Scarlett, J.M., Salman, M.D., New, J.G., \& Kass, P.H. (2002). “The role of veterinary practitioners in reducing dog and cat relinquishments and euthanasias". Journal of the American Veterinary Medical Association, 220:3, 306-311.

Scarlett, J.M., Salman, M.D., New, Jr, J.G., \& Kass, P.H. (1999). "Reasons for relinquishment of companion animals in US animal shelters: selected health and personal issues". Journal of Applied Animal Welfare Science, 2:1, 41-57.

Scott, J.P., \& Fuller, J.L. (1965). Genetics and Social Behavior of the Dog. Chicago: University of Chicago Press.

Scott, J.P., \& Marston, M.V. (1950). "Critical periods affecting normal and maladjustive social behavior in puppies". Journal of Genetic Psychology, 77, 25-6o.

Stallones, L., Marx, M., Garrity, T., \& Johnson, T. (1988). "Attachment to companion animals among older pet owners". Anthrozoös, 2, 118-124.

Serpell, J., \& Jagoe, J.A. (1995). "Early experience and the development of behaviour". In: J. Serpell (ed.), The Domestic Dog Its Evolution, Behaviour and Interactions with People. Cambridge: Cambridge University Press, 79-102.

Singer, P. (1983). Animal Liberation. London: Cape.

Singer, P. (1995). Animal Liberation, 2nd edition. London: Pimlico.

Sinski, J. (2016). “"A cat-sized hole in my heart”: public perceptions of companion animal adoption in the USA". In: M. Pręgowski (ed.), Companion Animals in Everyday Life. New York: Palgrave Macmillan, 73-89.

Svoboda, H.J., \& Hoffman, C.L. (2015). "Investigating the role of coat colour, age, sex, and breed on outcomes for dogs at two animal shelters in the United States". Animal Welfare, 24:4, 497-506.

Tiira, K., \& Lohi, H. (2006). "Early life experiences and exercise associate with canine anxieties". PLOS ONE, 10, e0141907.

USDA Animal and Plant Health Inspection Service (2018). Animal Welfare Act and Animal Welfare Regulations. 9CFR §2.1-2.12. Available online: https://www.aphis .usda.gov/animal_welfare/downloads/AC_BlueBook_AWA_FINAL_2017_508comp .pdf [Accessed December 12, 2018].

Virginia House Bill 538 (2008). Available online: https://legiscan.com/VA/bill/ HB538/2008 [Accessed March 21, 2018].

Von Borell, E. (1995). "Neurocrine integration of stress and significance of stress for the performances of farm animals". Applied Animal Behaviour Science, 44, 219-227.

Voris, H.C, Wittum, T.E., Rajala-Schultz, P.J., \& Lord, L.K. (2011). "Characterization of advertisements for puppies sold online: determinants of cost and a comparison with parent club breeders". Preventive Veterinary Medicine, 100:3-4, 200-209.

Vormbrock, J.K., \& Grossberg, J.M. (1988). "Cardiovascular effects of human-pet dog interactions". Journal of Behavioral Medicine, 11, 509-517. 
Webster, A.J.F. (2001). "Farm animal welfare: the five freedoms and the free market". The Veterinary Journal, 161, 229-237.

Weiss, E., Miller, K., Mohan-Gibbons, H., \& Vela, C. (2012). "Why did you choose this pet? Adopters and pet selection preferences in five animal shelters in the United States". Animals, 2, 144-159.

Wells, D. (2007). "Domestic dogs and human health: an overview". British Journal of Health Psychology, 12, 145 $-15^{6 .}$

Whyte, K.P., \& Thompson, P.B. (2012). "Ideas for how to take wicked problems seriously". Journal of Agricultural and Environmental Ethics, 25:4, 441-445. 